\title{
Normalisation Values For The Resonant Frequency Of The Middle Ear In Rats
}

\author{
Șule Mıdık ${ }^{1}$, Belde Çulhaoğlu², Selim Sermed Erbek ${ }^{3}$, Seyra Erbek ${ }^{4}$ \\ 1 MSc; Başkent University, Medical Faculty, ENT Department, Ankara - Turkey \\ 2 MSc; Başkent University, Medical Faculty, ENT Department, Ankara - Turkey \\ 3 MD Başkent University, Medical Faculty, ENT Department, Ankara - Turkey \\ 4 MD Başkent University, Medical Faculty, ENT Department, Ankara - Turkey
}

\begin{abstract}
Objective: In earlier studies, the resonant frequency (RF) of the middle ear has been investigated in a number of different animals. However, no study has so far specifically addressed the measurement of RF in rats. With this in mind, in our study, multifrequency tympanometry (MFT) was performed on rats and RF value measurements were taken. The aim was to ascertain the normal values for rats used in our university experiments and to provide guidance for further research to be undertaken in this area.
\end{abstract}

Materials and Methods: For the study, 16 male and 16 female adult Sprague Downey rats (32 animals, 64 ears) aged 10 months old and in healthy condition were used. MFT at $226 \mathrm{~Hz}$ frequency and above was performed on all the rats after they had been anaesthetised. In the first instance tympanograms were recorded using the $226 \mathrm{~Hz}$ probe tone, following which MFT measurements were

\section{Introduction}

Tympanometry is the measurement of the acoustic immitance of the ear as a function of the ear canal pressure (1). Since tympanometry is a basic, easy-to-apply and inexpensive method of evaluating middle ear function, it is one of the test batteries in frequent use in clinical settings (2). Multifrequency tympanometry (MFT) is performed at different frequencies between $200-2000 \mathrm{~Hz}$. It is a testing performed. RF values for the middle ear were determined in the range $200-2000 \mathrm{~Hz}$.

Results: For male rats, the mean RF value was 426.56 ( \pm $193.01 \mathrm{~Hz}$ ), whilst for female rats the mean was 496.88 $( \pm 132.55) \mathrm{Hz}$. When the values obtained for the male and female rats were compared, no statistically significant difference was observed between the two groups $(p=0.061)$. Accordingly, the mean RF value for the rats as a whole (obtained for 64 ears) was calculated to be 461.7 $( \pm 168.02) \mathrm{Hz}$.

Conclusion: In this research, RF values for the middle ear of rats has been demonstrated to be measurable. However, further research is needed into the relationship between RF and the characteristics of the middle ear in rats.

Key words: multifrequency tympanometry, resonant frequency, rat, normalisation
Correspondence: Belde Çulhaoğlu

Meraşal Fevzi Çakmak Cad. 5. Sok No:48 Bahçelievler/ ANKARA

e-mail: culhaoglubelde@gmail.com

Received: 12th, September, 2018; Accepted: 12th, November, 2018 method that provides information on the conductance of the outer ear and the admittance of the middle ear. The test gives information about the components that make up middle ear admittance: conductance, mass and stiffness (3). The most useful parameter obtained by MFT in a clinical setting is the middle ear resonant frequency (RF). RF may be defined as the frequency at which impedance is lowest and vibration highest within the middle ear. It is influenced 
by the mass and stiffness of the middle ear system $(4,5)$. RF is defined as the frequency at which the mass and stiffness effects are equal and balance each other out in the middle ear.

Values obtained with base and high frequency tone probes provide information about pathology. Whilst using the base frequency tone probe provides information about the tympanic membrane and middle ear stiffness, the high frequency tone probes supply key information about pathological processes that work through an effect on mass. MFT has gained an important role in differential diagnosis thanks to providing such information (6).

When we investigated the literature on research involving animal models and resonant frequency, we discovered a study performed on rabbits (7). However, no research into the use of MFT in rats has yet been reported, to the best of our knowledge. In the present study our aim was to demonstrate the resonant frequency in rats by using MFT.

\section{Materials And Methods}

This research was undertaken at the University Animal Experiments Laboratory with the approval of the University Animal Experiments Local Ethics Committee (Project No: DA16 / 29). The guidelines regarding animal care and usage as outlined in the International Declaration of Helsinki were complied with for the purposes of this study.

16 female and 16 male rats, totalling 32 rats in total, all aged 10 months, healthy and of Sprague Downey type were included in the study, the number indicated by the power calculation to be required. The mean weight of male rats included in the study was $352.5 \pm 33,61$ grams (range 309416 grams), whilst that of female rats was $254.44 \pm 31.04$ grams (range 187-310 grams). All the rats were maintained in cages within the same room and with identical ambient conditions, i.e. 12 hours light followed by 12 hours darkness, temperature $20-22^{\circ} \mathrm{C}$, free access to food and water and background noise kept below $50 \mathrm{~dB}$.

All the interventions were performed under general anaesthesia. Before taking any measurements, the rats first underwent otoscopy and the ear canals were cleared of any debris or plugs. To ensure general anaesthesia, the following drugs were given intraperitoneally: ketamine hydrochloride (Ketalar ampoules, Pfizer, Istanbul, Turkey) $60 \mathrm{mg} / \mathrm{kg}$, Xylazine ampoules, Bayer, Istanbul, Turkey) $6 \mathrm{mg} / \mathrm{kg}$.

The immitanciometric measurements were performed in all cases by means of a TympStar Middle Ear Analyz- er Version 2 immitanciometer (Grason-Stadler Inc, MN, USA) (Figure 1). First the $226 \mathrm{~Hz}$ tone probe was used to obtain a tympanogram and find the static admittance. A normal tympanogram curve was obtained for the rats using different frequencies. For the multifrequency measurements, the pressure was kept constant and resonance frequency values were obtained in consecutive fashion for the range $200-2000 \mathrm{~Hz}$, increasing the frequency stepwise by $50 \mathrm{~Hz}$ each time (Figure 2).

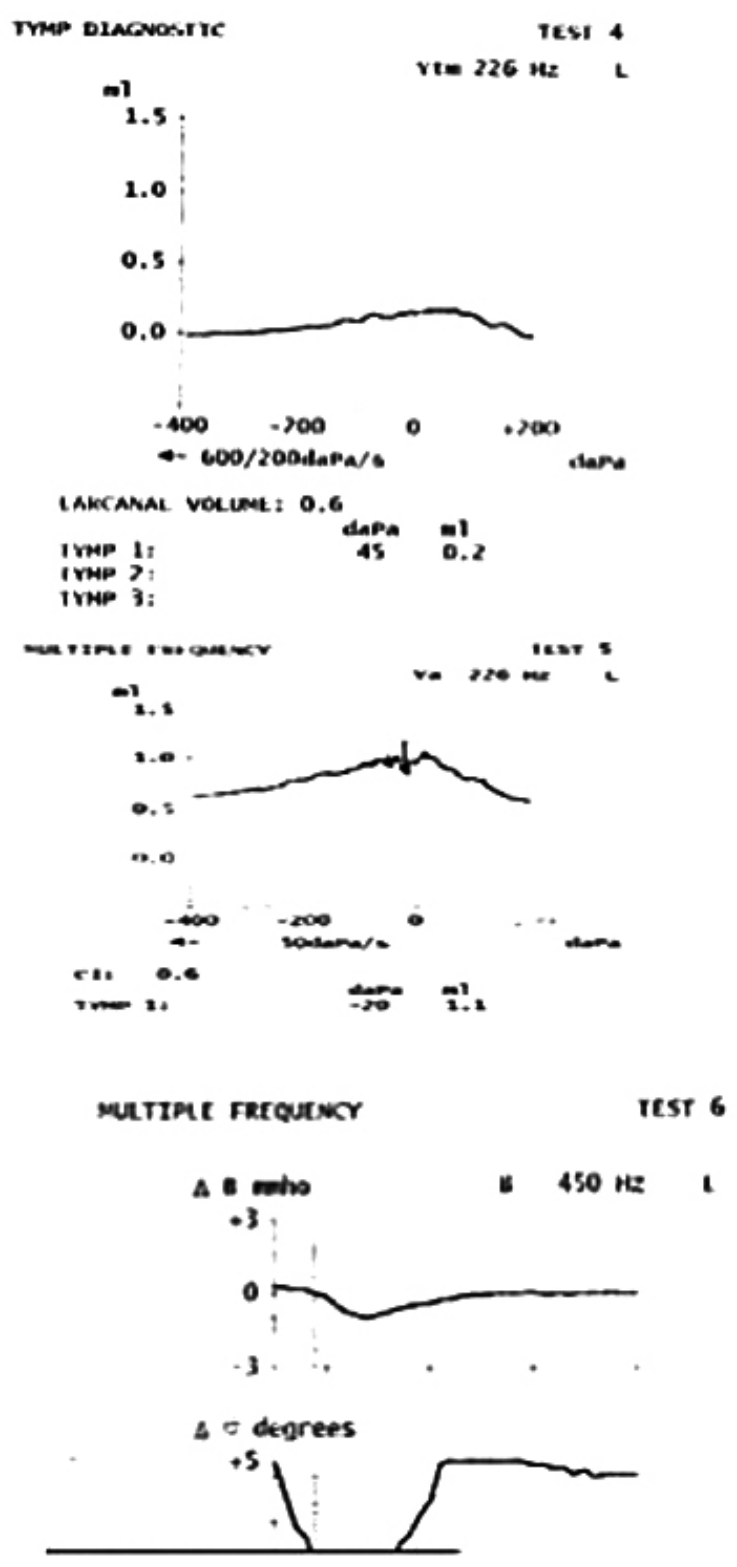

Figure 1. The immitanciometric measurement in a rat. 


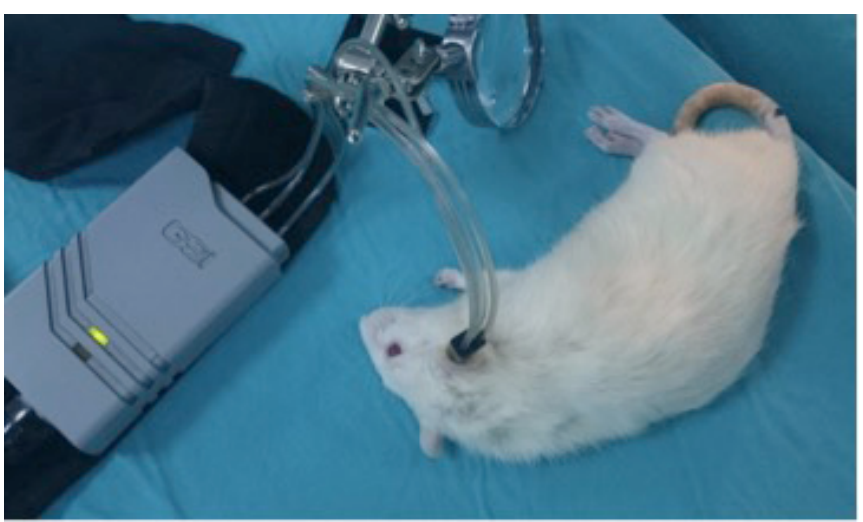

Figure 2. The MFT result for the left ear of one rat.

For the statistical analysis of the data obtained, the Statistical Package for the Social Sciences (SPSS Inc., Chicago, IL, USA) v22.0 application was used. Once all the data obtained had been recorded, Student's t-test and the Mann-Whitney $\mathrm{U}$ test were used to compare the means. A $p$ value of less than 0.05 was taken to indicate statistical significance.

\section{Results}

In this study, 16 male and 16 female rats (comprising 32 rats and 64 ears in total) were investigated to find out the value of the resonant frequency.

In all the rats, when the $226 \mathrm{~Hz}$ tone probe was applied for tympanometric analysis, the middle ear pressure was found to lie within the normal range (-50 to $+50 \mathrm{dePa}$ (decaPascals)).

The mean $\mathrm{RF}$ values for male rats were found to be $493.75( \pm 212.81) \mathrm{Hz}$ for the right ear, and $359.38( \pm$ 148.57) $\mathrm{Hz}$ for the left ear $(\mathrm{p}=0.379)$. The mean $\mathrm{RF}$ value for male rats as a whole was $426.56( \pm 193,01) \mathrm{Hz}$.

The mean RF values for female rats were $468.75( \pm$ 145.91) Hz for the right ear and $525( \pm 115.47) \mathrm{Hz}$ for the left ear ( $\mathrm{p}=0.379)$. The mean $\mathrm{RF}$ value for female rats as a whole was $496.88( \pm 132.55 \mathrm{~Hz})$.

When the values obtained for the male and female rats were compared, no statistically significant difference was observed between the two groups $(\mathrm{p}=0.061)$. Accordingly, the mean RF value for the rats as a whole (obtained for 64 ears) was calculated to be $461.7( \pm 168.02) \mathrm{Hz}$. The values obtained for the RF in rats are shown in Table 1.

\section{Discussion}

MFT is a reliable and easily performed test method used
Table 1: Demographic information of the experiment group and their RF values of right and left ears.

\begin{tabular}{|c|c|c|c|c|}
\hline NO & Weight (gr) & Male/Female & $\begin{array}{l}\text { Right Ear } \\
\text { RF (Hz) }\end{array}$ & $\begin{array}{l}\text { Left Ear RF } \\
(\mathrm{Hz})\end{array}$ \\
\hline 1 & 309 & M & 500 & 450 \\
\hline 2 & 416 & M & 450 & 650 \\
\hline 3 & 343 & M & 650 & 250 \\
\hline 4 & 336 & M & 850 & 250 \\
\hline 5 & 314 & M & 250 & 250 \\
\hline 6 & 406 & $M$ & 850 & 250 \\
\hline 7 & 321 & M & 450 & 450 \\
\hline 8 & 370 & M & 250 & 350 \\
\hline 9 & 328 & $M$ & 550 & 250 \\
\hline 10 & 313 & M & 400 & 250 \\
\hline 11 & 352 & M & 750 & 650 \\
\hline 12 & 380 & M & 600 & 550 \\
\hline 13 & 329 & M & 250 & 400 \\
\hline 14 & 383 & M & 250 & 250 \\
\hline 15 & 371 & M & 600 & 250 \\
\hline 16 & 369 & M & 250 & 250 \\
\hline NO & Weight (gr) & Male/Female & $\begin{array}{l}\text { Right Ear } \\
\text { RF }(\mathrm{Hz})\end{array}$ & $\begin{array}{l}\text { Left Ear RF } \\
(\mathrm{Hz})\end{array}$ \\
\hline 1 & 276 & $\mathrm{~F}$ & 550 & 450 \\
\hline 2 & 218 & $\mathrm{~F}$ & 250 & 450 \\
\hline 3 & 243 & $\mathrm{~F}$ & 600 & 650 \\
\hline 4 & 271 & $\mathrm{~F}$ & 700 & 550 \\
\hline 5 & 260 & $\mathrm{~F}$ & 500 & 450 \\
\hline 6 & 242 & $\mathrm{~F}$ & 500 & 550 \\
\hline 7 & 271 & $\mathrm{~F}$ & 250 & 500 \\
\hline 8 & 299 & $F$ & 400 & 550 \\
\hline 9 & 260 & $F$ & 500 & 650 \\
\hline 10 & 244 & $F$ & 250 & 550 \\
\hline 11 & 271 & $\mathrm{~F}$ & 550 & 250 \\
\hline 12 & 187 & $F$ & 250 & 550 \\
\hline 13 & 215 & $F$ & 600 & 400 \\
\hline 14 & 242 & $\mathrm{~F}$ & 600 & 750 \\
\hline 15 & 262 & $\mathrm{~F}$ & 500 & 500 \\
\hline 16 & 310 & $\mathrm{~F}$ & 500 & 600 \\
\hline
\end{tabular}


to assess the middle ear. It has been reported from experimental studies and certain animal studies that MFT offers benefit in the evaluation of disease $(8,9)$. In the literature, resonance frequency values have been examined in different animal models, but no research has been done on this problem in rats. In this study, RF values were measured and normal values established for rats by means of MFT.

Factors which variably affect the admittance of the middle ear include age, ethnicity and multiple other individual differences. Bearing these differences in mind, the normal values for $\mathrm{RF}$ are variable (10). In research involving tympanography in experimental animals, measurements were obtained at 226-678 and $1000 \mathrm{~Hz}$. Kiesling et al. report in their study of middle ear compliance that a tone probe using $226 \mathrm{~Hz}$ is suitable (11). When they compared the compliance values obtained in human subjects with those obtained in rabbits, the rabbit value was relatively low. It was shown that this value reflected the fact that the rabbit ear has greater stiffness compared to humans' (12). Cole et al. studied the values for dogs, obtaining tympanograms that demonstrated that the tympanographic curve altered under the influence of prolonged anaesthesia (8).

Stieve et al. (13) conducted research on rabbits. 36 female rabbits were used. They measured and compared values obtained at $226 \mathrm{~Hz}$, using multifrequency techniques, in animals pre- and post-right middle ear implantion surgery. The pre- and post-operative measurements showed the reproducibility of tympanometry using a frequency of $226 \mathrm{~Hz}$. It was determined through measurements taken at different intervals in the postoperative period that the resonant frequency had increased up to the 300th day post-op. This increase lends support to the conclusion that changes in connective tissue affect resonant frequency (14).

Rats are often chosen for research due to the similarity of rat ear anatomy to the human ear. They were also cho- sen for our study because they have similar characteristics to human ear and they can adapt easily to the environment in which they are housed. In our literature search, we did not identify any RF studies about rats. In the present experimental study, acoustic immitance was quantified in rats with the aim of using the normative values thus obtained in data analysis of subsequent experimental studies. The rats included in our study were of the same age as each other because age and age-related maturation affect the width of the ear canal and hence alter acoustic energy transfer.

Human subject research studies that have looked at the effect of sex on RF have shown that the RF in females is higher than that obtained for males (15). However, in our research, when the mean values for RF were compared between male and female rats, no difference at the level of statistical significance was detected. Therefore, we calculated the value for RF on the basis of the rats as a whole.

\section{Conclusion}

This study was planned with a view to ascertaining normal values for use in our university research, to broaden the use of MFT clinically, and to shed light on the other studies in this area. The findings of our study suggest that the middle ear can also be successfully modelled in rats. The data obtained in this research are preliminary results. Further research into the relationship between the structural and histological features of the middle ear and RF should be pursued.

Conflict of Interest: There is no conflict of interest to declare for this study.

Financial support: This study was supported by the Research Fund of Baskent University.

\section{References}

1. Terkildsen K, Thomsen K. The influence of pressure variations on the impedance of the human ear drum. J Laryngol Otology 1959; 73: 409-418.

2. Holte L. Aging effects in multifrequency tympanometry. Ear Hear 1996; 17:12-18.

3. Iacovou E, Vlastarakos P.V, Ferekidis E, Nikolopoulos T.P. Multi-Frequency Tympanometry: Clinical Applications for the Assesment of the Middle Ear Status. Indian J Otolaryngol Head Neck Surg 2013; 65(3):283-287.

4. Prabhu P, Manandhar S, Nasima Ahmed B. Test-Retest Reliability of the Components of Multi-Frequency Tympanometry. J International Advanced Otology 2017; 13(1): 74-6.

5. Öz I. Meniere hastalığında gliserol testi ile rezonans frekans farklılığının değerlendirilmesi. Başkent Üniversitesi Sağlı Bilimleri Enstitüsü, Yüksek Lisans Tezi.2018.

6. Margolis RH, Van Camp KJ, Wilso RH. Multifrequency tympanometry in normal ears. J. Audiology 1985; 24: 44-53.

7. Lehnhardt E, Laszig R., Praxis der Audiometrie. Stuttgart, Georg Thieme, 2001.

8. Abou-Elhamd KE, Abd-Ellatif AE, Sultan MA. The role of multifrequency tympanometry in otitis media. Saudi Med J. 2006; Vol.27(3): 357-360. 
9. Cole LK, Podell M, Kwochka KW. Impedance audiometry measurements in clinically normal dogs. American Journal of Veterinary Research 2000; 61: 442-5

10. Shanks J, Shelton C. Basic principles and clinical applications of tympanometry. Clin Audioly. 1991; 24: 299-328.

11. Kiessling J. Impedanzaudiometrie in der HNO Fachpraxis. In: HNO Praxis Heute (Ganz H, Schätzle W, editörler). 5-26, Springer-Verlag, New York, 1982.

12. Rosowski J., Outer and Middle Ears. In: Comparatitive Hearing in Mammals (Fay R, Popper A, editör)., s172-237, New York, Springer-Verlag, 1994.
13. Stieve M, Mojallal H, Battmer R.D, Winter M, Lenarz T., Multifrequency tympanometry: Experimental application after implantation of ossicular replacement prosthesis in rabbits. Otology and Neurotology 2007; 28:875Y877.

14. Steinbach E, Vergleichende untersuchungen an gehörknöchelchen und knochentransplantaten beim kaninchen und menschen. Medizinische Fakultät Tübingen Habilitationsschrift 1973; 31-2.

15. Wiley TL, Cruickshanks KJ, Nondahl DM, Tweed TS. Self- reported hearing handicap and audiometric measures in older adults. Journal of the American Academy of Audiology 1999; 10: 173-179.

This is an open access article distributed under the terms of the Creative Commons Attribution-NonCommercial-NoDerivs 3.0 Unported (CC BY- NC-ND3.0) Licence (http://creativecommons.org/licenses/by-nc-nd/3.0/) which permits unrestricted noncommercial use, distribution, and reproduc- tion in any medium, provided the original work is properly cited.

Please cite this article as: Mıdık Ş, Çulhaoğlu B, Erbek S. S., Erbek S, Normalisation Values For The Resonant Frequency Of The Middle Ear In Rats. ENT Updates 2018;8(3): 170-174. 